\title{
PRÉCIS OF MEANING IN LIFE: AN ANALYTIC STUDY ${ }^{1}$
}

\section{THADDEUS METZ}

\section{University of Johannesburg}

In Meaning in Life: An Analytic Study (Metz 2013), my overarching aims are to articulate a novel theory of what would make a human person's life meaningful and to argue that it is more justified than competitors to be found in the analytic philosophical literature from the past 100 or so years.

This project inherently brings with it certain limitations. In focusing on the meaning of an individual's life, I set aside the issue of what, if anything, might confer meaning on the human race in general. In evaluating theories of meaning in a person's life, I address fundamental principles that purportedly capture what all meaningful conditions have in common, and so do not explore particularist, phenomenological, strictly first-personal or other philosophical approaches that one might adopt. In considering principally analytic texts, i.e., those in the Englishspeaking, Anglo-American philosophical tradition, I do not thoroughly discuss those in other traditions such as the Continental or East Asian. Finally, in reflecting mainly on philosophical works, I bracket considerations of how research in other fields such as psychology or religion might be revealing.

Given such a focus, I found more than enough authors, works and ideas with which to grapple in Meaning in Life. The contributors to this special issue of the European Journal for Philosophy of Religion have by and large elected to stay within the parameters of my project; the debates are immanent to the tradition of analytic philosophy.

In the rest of this overview, I provide a sketch of the three major parts of Meaning in Life, which will set the stage for the debates that follow. In the first major part of the book, I analyze the category of

\footnotetext{
${ }^{1}$ Much of this précis borrows from a previous one that I had articulated (Metz 2015).
} 
meaningfulness in a way that is intended to be largely neutral amongst competing theories of what meaningfulness essentially is. Specifically, I define what most in Anglo-American philosophy mean by the phrase 'meaning in life' and cognate terms, indicate what the bearer of this value is, and differentiate meaningfulness from happiness, subjectively construed.

With regard to definitional matters, I ultimately maintain that a pluralist, family resemblance model is most defensible at this point. According to this view, talk of 'meaning in life' is about ideas such as purposiveness, transcendence, aptness of emotions such as admiration and esteem, and (I would add now) narrative properties. While each of these ideas captures a large array of theoretical work in the relevant literature, no one of them captures everything on its own.

I next consider what the bearer of life's meaning is, i.e., what it is about a life that can be meaningful or meaningless. Is it only the life as a patterned whole, merely the parts of a life considered in themselves, or both? I conclude in favour of the latter, mixed view; I maintain that there are two independent dimensions of meaning in life, namely, certain parts of a person's life at a certain time, such as a particular action, project or stage (e.g., adolescence) and then also the person's life considered in its entirety. A complete judgment of the degree of meaning in a person's life, which would ground a comparison with the lives of others, must weigh up both dimensions and add them together in some way.

In the rest of part one, I compare and contrast the goods of pleasure and meaning, focusing most on highlighting important differences between them. I contrast pleasure and meaning with respect to six valuetheoretic factors, amongst them: what the logical sources of these values are in contrast to their bearers, how luck can play a role in the realization of the values, and which attitudes are appropriate in response to them. I conclude by suggesting that a pleasant life is plausibly to be identified with a happy one, which means that happiness and meaningfulness are two distinct goods that can each contribute independently to making a life choice-worthy.

In the next two major parts of the book, I focus on spelling out and evaluating a wide array of theories of life's meaning, basic accounts of what all the meaningful conditions of a life have in common as distinct from the meaningless ones. I assess theories largely in terms of the extent to which they plausibly entail and powerfully explain intuitions salient in the analytic philosophical literature, particularly as they concern 
the meaningfulness of the good (morality, beneficence), the true (knowledge, wisdom) and the beautiful (art, creativity).

Specifically, in the second part, I criticize supernaturalist theories of meaning in life, according to which either God or a soul (or both), as typically conceived in the monotheist tradition, is necessary for life to be at all meaningful. I spend considerable time focusing on the most influential version of supernaturalism, according to which meaning in a person's life consists of her fulfilling God's purpose.

I provide reasons to doubt arguments in favour of purpose theory, and also claim to offer a novel reason to doubt the view itself. According to this latter argument, in order for God to be necessary to confer meaning on our lives, God would have to be qualitatively different from, and higher than, anything that could exist in the natural world. And this means that God would have to be a person who has properties such as simplicity and atemporality, properties that are difficult to reconcile with purposive agency as normally conceived by monotheists, which appears to be essentially complex and temporal.

I also proffer arguments against any supernaturalism, not just the purposive version of it. The most original objection is that many of those who adopt supernaturalism hold views that are in tension with each other. On the one hand, they claim to know that some lives have meaning in them, but, on the other, they claim not to know that anything supernatural actually exists, making it incoherent to claim to know that meaning logically depends on the supernatural. Supernaturalists might have faith in a spiritual realm, but that is of course not knowledge of its existence, which most implicitly maintain they have about the presence of meaning in people's lives.

In the third part of Meaning in Life, I present a new naturalist theory that I contend improves upon extant versions of naturalism, the broad view that a life in a purely physical world could be meaningful. I first provide counterexamples to a wide range of existing naturalist views, including the theories that a life is meaningful just insofar as it is creative, promotes welfarist or perfectionist consequences in the long run, or connects with organic unities beyond itself.

I then advance my favoured view at this stage, the fundamentality theory, which is roughly the idea that a life is (particularly) meaningful insofar as exercises reason, does so in a robust, sophisticated way, and orients it towards basic conditions of human existence, ones that are largely responsible for or explain much else about it. 
Just as $\mathrm{H}_{2} \mathrm{O}$ is fundamental to water, and being a CEO is fundamental to the operations of a firm, so there are certain properties of human life that are fundamental to (i.e., roughly, account for much of) various dimensions of it. For example, space-time, gravity and light are fundamental to the environment in which human beings live; communication, socialization and labour are fundamental to the development of the human species; practical reasoning and communion are fundamental to the course of a human society; and character is fundamental to the way a particular one of us lives (an additional dimension that I did not discuss in the book).

By my theory, great meaning in a life comes from using rationality in complex, willful ways to positively engage with these kinds of 'deep' facets of human life. Sometimes that is a matter of discovering or learning what they are; other times it is a matter of protecting them; and still other times it is a matter of expressing respect for or appreciation of them.

I do not claim that the fundamentality theory is perfect, as it stands. However, I continue to be inclined to think that it is the best springboard for future reflection. It, better than existing rivals in the literature, captures intuitions about the good, the true and the beautiful as central to meaning, intuitions that are salient in the analytic philosophical literature. Or so I argue in the book, a large claim that readers should consider in light of the contributions to this issue of the European Journal for Philosophy of Religion.

\section{BIBLIOGRAPHY}

Metz, Thaddeus. 2013. Meaning in Life: An Analytic Study (Oxford: Oxford University Press)

Metz, Thaddeus. 2015. 'Précis of Meaning in Life: An Analytic Study', in Masahiro Morioka (ed.), Reconsidering Meaning in Life (Saitama, Japan: Waseda University), pp. ii-vi 